\title{
Established risk factors for coronary heart disease are unrelated to androgen-induced baldness in female-to-male transsexuals
}

\author{
E J Giltay, A W F T Toorians, A R Sarabdjitsingh, N A de Vries \\ and $\mathbf{L} \mathbf{J} \mathbf{G}$ Gooren
} Department of Endocrinology, Andrology Unit, Vrije University Medical Center, Amsterdam, The Netherlands
(Requests for offprints should be addressed to E J Giltay, Psychiatric Center GGZ Delfland, PO Box 5016, 2600 GA Delft, The Netherlands;
Email: giltay@dds.nl)

\begin{abstract}
A high scalp sensitivity to androgens is part of the pathophysiology of male-pattern baldness (MPB). Androgens affect established risk factors for coronary heart disease (CHD), and a supposedly heightened impact on these risk factors is hypothesized to explain the epidemiological association between MPB and CHD. In this retrospective, observational study we studied 81 femaleto-male transsexual $(\mathrm{F} \rightarrow \mathrm{M})$ subjects, mean age 36.7 years (range 21-61), treated with testosterone esters $(n=61$; $250 \mathrm{mg} \mathrm{i.m./2} \mathrm{weeks)} \mathrm{or} \mathrm{testosterone} \mathrm{undecanoate}(n=20$; $160-240 \mathrm{mg} /$ day orally). The degree of MPB was selfassessed using a 5-point scale (i.e. type I (no hair loss) to type V (complete hair loss)). Body mass index, blood pressure and levels of lipid and insulin were retrospectively
\end{abstract}

assessed at the start of testosterone administration (0.5-24 years before) and between 3 and 4 months of follow-up. We found that 31 of $81 \quad(38 \cdot 3 \%) \quad \mathrm{F} \rightarrow \mathrm{M}$ transsexuals had MPB type II-V. Thinning of hair was related to the duration of androgen administration and present in about $50 \%$ of $\mathrm{F} \rightarrow \mathrm{M}$ transsexuals after 13 years. None of the CHD risk factors at follow-up, nor proportional changes, was associated with the degree MPB, except that there was an unexpected tendency of lower fasting glucose levels in balding subjects. Therefore, our findings do not support the idea that MPB serves as an indicator of increased CHD risk through androgenic effects on classic CHD risk factors.

Journal of Endocrinology (2004) 180, 107-112

\section{Introduction}

Several cohort (Herrera et al. 1995, Schnohr et al. 1995, Ford et al. 1996, Lotufo et al. 2000, Matilainen et al. 2001) and a case-control study (Lesko et al. 1993) have shown an association between the degree of male-pattern baldness (MPB) and myocardial infarction, coronary heart disease (CHD) events and CHD mortality. Established CHD risk factors are typically found in the metabolic syndrome and the common endocrine disorder of polycystic ovary syndrome (PCOS) (Laws \& Reaven 1993, Dunaif 1997), including hyperinsulinemia, glucose intolerance, high fasting triglycerides, low high-density lipoprotein (HDL)cholesterol, hypertension and obesity (Dunaif 1997). Androgenic alopecia has also been associated with PCOS in some (Ferriman \& Purdie 1979, Dunaif 1997) but not all studies (Legro et al. 2002).

While cohort and case-control studies are useful instruments in finding associations, they cannot explain the association between MPB and CHD. It has been hypothesized that high androgen levels or activity may explain this association. Androgens can induce MPB in genetically susceptible men and women (Price 1999, Signorello et al. 1999), and can also alter lipid profiles (Glazer 1991) and other established CHD risk factors (Asscheman et al. 1994, Elbers et al. 2003). Three previous studies found support for a possible association between MPB and a higher serum cholesterol and blood pressure (Trevisan et al. 1993, Lotufo et al. 2000) or disorders clustered in the metabolic syndrome (Matilainen et al. 2000). Another study, however, found no evidence for an intermediate role of established CHD risk factors (Ellis et al. 2001). These studies cannot reveal whether androgens form the link between MPB with CHD risk factors. We were able to study the effects of androgen administration in female-to-male $(\mathrm{F} \rightarrow \mathrm{M})$ transsexuals, who requested hormonal induction of secondary sex characteristics of the opposite sex (Giltay \& Gooren 2000). We have related androgen-induced changes in CHD risk factors in the first 3 months of treatment with MPB which occurred years later. During these first months of treatment the main changes in CHD risk factors occur, yielding more statistical power. Thus, we analyzed (i) the temporal effects of exogenous androgens on MPB in biological women, and (ii) the association between androgeninduced MPB and (changes in) established CHD risk factors to investigate whether MPB is associated with CHD risk factors. 


\section{Subjects and Methods}

All consecutive $\mathrm{F} \rightarrow \mathrm{M}$ transsexuals were approached for this study between January and July 2002. The degree of MPB was assessed by way of a self-assessment questionnaire using a 5-point scale (i.e. type I (no loss) to type $\mathrm{V}$ (complete hair loss at the crown); Fig. 1) (Lotufo et al. 2000), based on the scale by Norwood (1975). The questionnaire was filled in by 81 Caucasian $\mathrm{F} \rightarrow \mathrm{M}$ transsexuals with a mean age of $36 \cdot 7$ years (range 21-61). $\mathrm{F} \rightarrow \mathrm{M}$ transsexuals were treated either with $250 \mathrm{mg} /$ 2 weeks of testosterone esters i.m. $(n=61)$ (Sustanon; Organon, Oss, The Netherlands) or with $160-240 \mathrm{mg} /$ day oral testosterone undecanoate $(n=20) \quad$ (Andriol; Organon) following the patient's preference. For diagnosis and treatment, guidelines of the Harry Benjamin International Gender Dysphoria Association were followed (Walker et al. 1985). Testosterone administration aimed to reach serum testosterone levels within the normal range for men. We assumed that no MPB occurred prior to treatment and that any MPB was caused by androgen treatment. Androgen treatment started between 1977 and 2001 at our department and had a median duration of 8 years (range 0.5-24 years). None of the subjects was taking lipid-lowering therapy. The body mass index (BMI) was calculated as the weight in kilograms divided by the square of the height in meters and was a mean of $23 \cdot 0 \mathrm{~kg} / \mathrm{m}^{2}$ (S.D. $4 \cdot 6$; range $15 \cdot 6-41 \cdot 0$ ) at baseline. Systolic (SBP) and diastolic blood pressure (DBP) were taken and the mean arterial pressure (MAP; i.e. $\mathrm{DBP}+(\mathrm{SBP}-$ DBP)/3) was calculated.

Retrospectively, we gathered baseline (i.e. before the start of androgen administration) as well as 3-4 month values of all parameters. We only used these values, because in our previous studies the strongest androgeninduced changes were found during the first months (Elbers et al. 2003), which consequently provides the strongest discriminating power to detect individual androgen-induced changes in CHD risk factors. In fasting blood samples we assessed levels of glucose (hexokinase method; Boehringer Mannheim), insulin (IRMA; Biosource Diagnostics, Fleurus, Belgium), HDL-cholesterol, low-density lipoprotein (LDL)cholesterol, total cholesterol and triglycerides (enzymatic colorimetric method; Boehringer Mannheim), testosterone (Coat-A-Count; Diagnostics Products Corporation, Los Angeles, CA, USA), 17 $\beta$-estradiol (Sorin Biomedica, Saluggia, Italy), luteinizing hormone (LH) and follicle-stimulating hormone (FSH) (Amerlite Immunometric Luminescence Assay; Amersham). Complete laboratory values were available in 56 subjects. Measurements were performed within the scope of several studies, all of which had been approved by the Ethics Review Board of the Vrije University Medical Center in Amsterdam, and all subjects gave their informed consent to the present study.
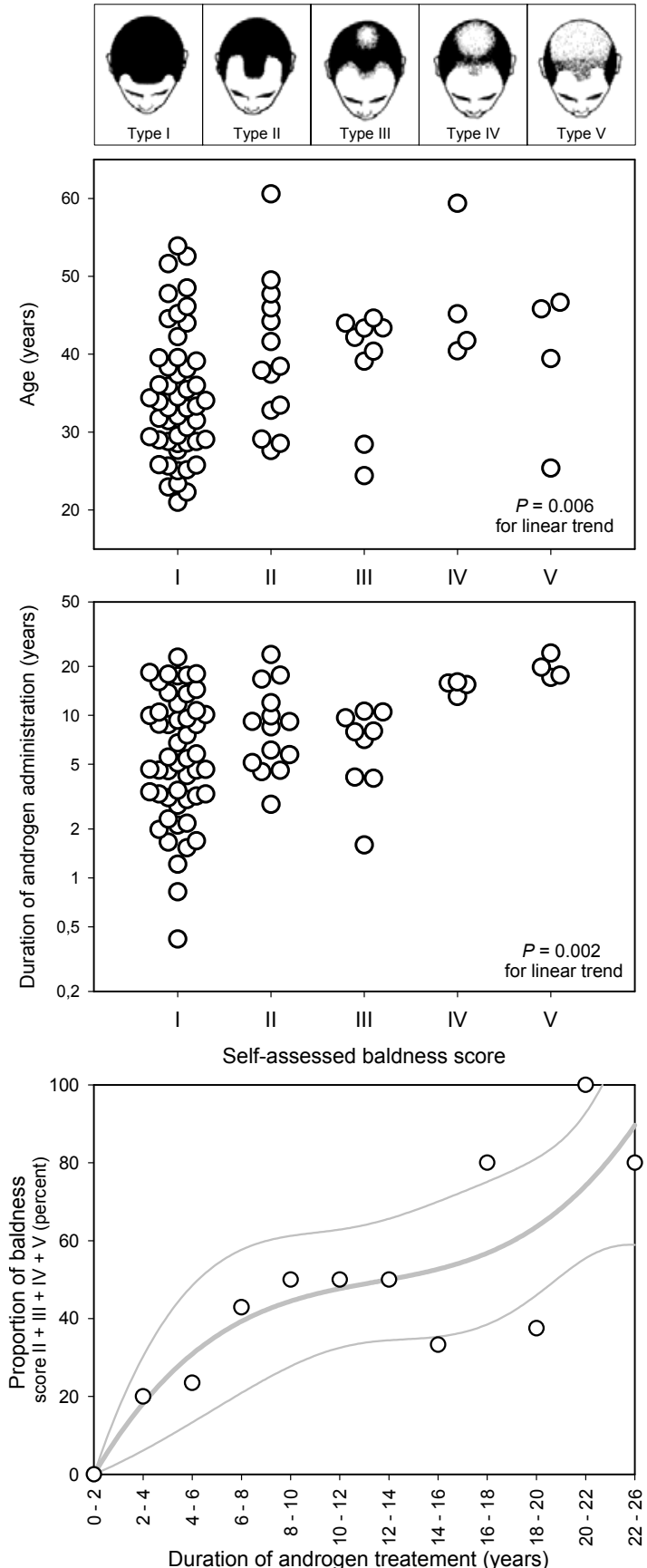

Figure 1 The two upper plots show the positive association of baldness with increasing age and duration of treatment. The spline plot (with 95\% confidence intervals) shows the association of duration of treatment and MPB, which suggests that after about 13 years of androgen administration $50 \%$ of $\mathrm{M} \rightarrow \mathrm{F}$ transsexuals have developed thinning of the hair (baldness score II-V).

Variables with right-skewed distributions (i.e. testosterone, $17 \beta$-estradiol, LH, FSH, triglycerides and insulin) were logarithmically transformed before analysis. ANOVA 
Table 1 Characteristics of $\mathrm{F} \rightarrow \mathrm{M}$ transsexuals before and upon testosterone administration. Testosterone, $17 \beta$-estradiol, $\mathrm{LH}, \mathrm{FSH}$, triglycerides and insulin were logarithmically transformed before analyses. Data are either means \pm S.D. or, for logarithmically transformed values, medians ( 25 and 75 percentiles)

\begin{tabular}{|c|c|c|c|}
\hline & Baseline & $\begin{array}{l}\text { 3-4 months } \\
\text { of follow-up }\end{array}$ & $P$-value* \\
\hline \multicolumn{4}{|l|}{ Variable } \\
\hline Testosterone (nmol/l) & $1 \cdot 2(0 \cdot 5-1 \cdot 8)$ & $30 \cdot 0(16 \cdot 0-42 \cdot 5)$ & $<0.001$ \\
\hline $17 \beta$-Estradiol $(\mathrm{pmol} / \mathrm{l})$ & $167(102-265)$ & $139(106-163)$ & $0 \cdot 044$ \\
\hline $\mathrm{LH}(\mathrm{U} / \mathrm{l})$ & $3 \cdot 7(2 \cdot 3-5 \cdot 5)$ & $1 \cdot 8(0 \cdot 6-3 \cdot 6)$ & $<0.001$ \\
\hline $\mathrm{FSH}(\mathrm{U} / \mathrm{I})$ & $4 \cdot 4(3 \cdot 5-6 \cdot 1)$ & $3 \cdot 4(1 \cdot 4-4 \cdot 9)$ & $0 \cdot 002$ \\
\hline BMI $\left(\mathrm{kg} / \mathrm{m}^{2}\right)$ & $22 \cdot 89 \pm 4 \cdot 53$ & $24 \cdot 46 \pm 3 \cdot 85$ & $<0.001$ \\
\hline $\mathrm{SBP}(\mathrm{mmHg})$ & $126 \cdot 62 \pm 13 \cdot 14$ & $122 \cdot 02 \pm 10 \cdot 75$ & 0.005 \\
\hline $\mathrm{DBP}(\mathrm{mmHg})$ & $79 \cdot 80 \pm 8 \cdot 00$ & $77 \cdot 72 \pm 6 \cdot 81$ & 0.032 \\
\hline $\mathrm{MAP}(\mathrm{mmHg})$ & $142 \cdot 11 \pm 15 \cdot 70$ & $136 \cdot 74 \pm 12 \cdot 85$ & 0.006 \\
\hline Total cholesterol (mmol/l) & $4.57 \pm 0.87$ & $4.53 \pm 1 \cdot 12$ & 0.656 \\
\hline HDL-cholesterol (mmol/l) & $1 \cdot 41 \pm 0 \cdot 43$ & $1 \cdot 14 \pm 0 \cdot 29$ & $<0.001$ \\
\hline LDL-cholesterol (mmol/l) & $2 \cdot 72 \pm 0 \cdot 86$ & $3 \cdot 03 \pm 1 \cdot 14$ & 0.002 \\
\hline $\mathrm{HDL} / \mathrm{LDL}$ ratio & $0 \cdot 59 \pm 0 \cdot 31$ & $0 \cdot 42 \pm 0 \cdot 18$ & $<0.001$ \\
\hline Triglycerides $(\mathrm{mmol} / \mathrm{l})$ & $0.70(0.55-1 \cdot 20)$ & $0.80(0 \cdot 60-1 \cdot 05)$ & 0.766 \\
\hline Glucose $(\mathrm{mmol} / \mathrm{l})$ & $5 \cdot 22 \pm 1 \cdot 26$ & $4.90 \pm 0.67$ & 0.002 \\
\hline Insulin $(\mathrm{pmol} / \mathrm{l})$ & $47 \cdot 0(32 \cdot 0-73 \cdot 0)$ & $42 \cdot 0(30 \cdot 3-52 \cdot 0)$ & 0.055 \\
\hline
\end{tabular}

${ }^{*} P$-values by the $t$-test for paired samples.

trend analyses were used to seek for linear trends between the degree of baldness and risk factors for CHD. Independent-sample $t$-tests, paired-sample $t$-tests, ANOVA and a multivariate general linear model were used as appropriate. Proportional changes were calculated as the ratio of the 3-month value over the baseline value $(\times 100 \%)$. If measurements appeared to be below the lower limit of detection, the value of that lower limit divided by 2 was used for statistical analyses. Analyses were performed with SPSS $8 \cdot 0$.

\section{Results}

Table 1 shows the changes upon testosterone administration. Serum levels of testosterone increased significantly, whereas $17 \beta$-estradiol, LH and FSH decreased significantly. BMI increased and the SBP, DBP and MAP decreased. Both insulin and glucose levels decreased. HDL-cholesterol levels decreased by $17 \%$, whereas LDLcholesterol levels increased by $13 \%$, leading to a $22 \%$ decrease in the ratio of HDL to LDL. No statistically significant changes were found for total cholesterol and triglyceride levels.

The $81 \mathrm{~F} \rightarrow \mathrm{M}$ transsexuals classified themselves as MPB type I $(n=50 ; 61 \cdot 7 \%)$, II $(n=14 ; 17 \cdot 3 \%)$, III $(n=9 ; 11 \cdot 1 \%)$, IV $(n=4 ; 4.9 \%)$ and $\mathrm{V}(n=4 ; 4 \cdot 9 \%)$. There were no baseline differences between subjects who later developed MPB type I vs MPB type II-V for any of the measurements (i.e. testosterone, 17 $\beta$-estradiol, LH, FSH, BMI, SBP, DBP, MAP, total-, HDL- and LDL-cholesterol, $\mathrm{HDL} / \mathrm{LDL}$ ratio, triglycerides, glucose or insulin). As expected, MPB was significantly related to age and the duration of treatment (Fig. 1). Spline plots showed that after 13 years of androgen administration, hair loss (type II-V) had started in about $50 \%$ of $\mathrm{F} \rightarrow \mathrm{M}$ transsexuals (Fig. 1). A more severe MPB type III-V was present in $50 \%$ of $\mathrm{F} \rightarrow \mathrm{M}$ transsexuals only after 24 years of androgen administration. The $61 \mathrm{~F} \rightarrow \mathrm{M}$ transsexuals treated with parenteral testosterone had a similar degree of hair loss as compared with the $20 \mathrm{~F} \rightarrow \mathrm{M}$ transsexuals treated with oral testosterone undecanoate $(P=0 \cdot 28)$.

Because of the low number of subjects with class II, III and IV type of baldness, these three classes were collapsed in further analyses. None of the CHD risk factors (i.e. blood pressure, BMI, levels of lipids and insulin) at 3-4 months was associated with the degree of hair loss, except for lower fasting glucose levels in more severely balding subjects (Table 2), a finding that contrasts with our hypothesis. In particular, the strong and consistent change in the ratio of HDL- over LDL-cholesterol was not related to the degree of hair loss. The proportional changes during the first 3-4 months of treatment were neither related to the degree of hair loss (data not shown). Adjusting for treatment duration, age and the route of administration (oral or parenteral) had no influence (data not shown).

\section{Discussion}

It has been hypothesized that androgens link MPB and established CHD risk factors, and consequently explain the higher rate of CHD in balding men (Lesko et al. 1993, Herrera et al. 1995, Schnohr et al. 1995, Ford et al. 1996, 
Table 2 Comparing established CHD risk factors at 3-4 months of androgen administration in $81 \mathrm{~F} \rightarrow \mathrm{M}$ transsexuals between different categories of MPB (i.e. androgenic alopecia). Testosterone, 17ß-estradiol, LH, FSH, triglycerides and insulin were logarithmically transformed before analyses. Data are either means \pm S.D. or, for logarithmically transformed values, medians (25 and 75 percentiles)

\begin{tabular}{|c|c|c|c|c|c|}
\hline & $\begin{array}{l}\text { Non-balding (type I) } \\
(n=50)\end{array}$ & $\begin{array}{l}\text { Balding (type II) } \\
(n=14)\end{array}$ & $\begin{array}{l}\text { Balding (type III+IV+V) } \\
(n=17)\end{array}$ & $P$-value ${ }^{*}$ & $P$-value ${ }^{* *}$ \\
\hline \multicolumn{6}{|l|}{ Variable } \\
\hline Testosterone $(\mathrm{nmol} / \mathrm{l})$ & $30 \cdot 2(15 \cdot 7-39 \cdot 7)$ & $33 \cdot 3(21 \cdot 8-60 \cdot 5)$ & $20 \cdot 5(5 \cdot 4-46 \cdot 9)$ & $0 \cdot 77$ & $0 \cdot 51$ \\
\hline $17 \beta$-Estradiol $(\mathrm{pmol} / \mathrm{l})$ & $144(111-175)$ & $129(95-150)$ & $127(107-188)$ & $0 \cdot 48$ & $0 \cdot 55$ \\
\hline $\mathrm{LH}(\mathrm{U} / \mathrm{l})$ & $2 \cdot 0(0 \cdot 6-3 \cdot 6)$ & $2 \cdot 1(1 \cdot 1-5 \cdot 4)$ & $1 \cdot 1(0 \cdot 4-2 \cdot 3)$ & $0 \cdot 44$ & $0 \cdot 26$ \\
\hline $\mathrm{FSH}(\mathrm{U} / \mathrm{I})$ & $3 \cdot 2(1 \cdot 0-5 \cdot 1)$ & $4 \cdot 4(3 \cdot 1-5 \cdot 5)$ & $2 \cdot 7(1 \cdot 5-3 \cdot 7)$ & $0 \cdot 39$ & $0 \cdot 12$ \\
\hline BMI $\left(\mathrm{kg} / \mathrm{m}^{2}\right)$ & $24 \cdot 1 \pm 3 \cdot 0$ & $25 \cdot 7 \pm 3 \cdot 7$ & $25 \cdot 4 \pm 5 \cdot 1$ & $0 \cdot 12$ & $0 \cdot 21$ \\
\hline $\mathrm{SBP}(\mathrm{mmHg})$ & $122 \cdot 2 \pm 10 \cdot 5$ & $123 \cdot 8 \pm 11 \cdot 2$ & $120 \cdot 1 \pm 10 \cdot 3$ & $0 \cdot 59$ & $0 \cdot 63$ \\
\hline DBP (mmHg) & $77 \cdot 0 \pm 7 \cdot 5$ & $79 \cdot 4 \pm 6 \cdot 8$ & $78 \cdot 2 \pm 5 \cdot 5$ & $0 \cdot 43$ & $0 \cdot 53$ \\
\hline MAP (mmHg) & $137 \cdot 3 \pm 12 \cdot 5$ & $138 \cdot 5 \pm 13 \cdot 0$ & $134 \cdot 0 \pm 12 \cdot 5$ & $0 \cdot 45$ & $0 \cdot 67$ \\
\hline Total cholesterol (mmol/l) & $4 \cdot 4 \pm 0 \cdot 8$ & $5 \cdot 1 \pm 1 \cdot 7$ & $4 \cdot 5 \pm 1 \cdot 2$ & $0 \cdot 39$ & $0 \cdot 12$ \\
\hline HDL-cholesterol (mmol/l) & $1 \cdot 10 \pm 0 \cdot 24$ & $1 \cdot 24 \pm 0 \cdot 29$ & $1 \cdot 14 \pm 0 \cdot 38$ & $0 \cdot 42$ & $0 \cdot 34$ \\
\hline LDL-cholesterol (mmol/l) & $2 \cdot 91 \pm 0.90$ & $3 \cdot 47 \pm 1 \cdot 55$ & $3 \cdot 04 \pm 1 \cdot 22$ & $0 \cdot 44$ & $0 \cdot 33$ \\
\hline $\mathrm{HDL} / \mathrm{LDL}$ ratio & $0 \cdot 41 \pm 0 \cdot 16$ & $0 \cdot 43 \pm 0 \cdot 23$ & $0 \cdot 42 \pm 0 \cdot 19$ & $0 \cdot 88$ & 0.98 \\
\hline Triglycerides (mmol/l) & $0.82(0.65-1.04)$ & $0.65(0.60-1.55)$ & $0.90(0.52-1 \cdot 12)$ & $0 \cdot 82$ & 0.97 \\
\hline Glucose $(\mathrm{mmol} / \mathrm{l})$ & $5 \cdot 01 \pm 0 \cdot 74$ & $4.67 \pm 0.33$ & $4.47 \pm 0.60$ & 0.02 & 0.06 \\
\hline Insulin (pmol/l) & $43 \cdot 2(34 \cdot 1-53 \cdot 2)$ & $36 \cdot 5(28 \cdot 0-58 \cdot 5)$ & $34 \cdot 0(21 \cdot 0-55 \cdot 5)$ & $0 \cdot 09$ & $0 \cdot 22$ \\
\hline
\end{tabular}

${ }^{*} P$-values by the weighted linear term in an ANOVA.

**P-values corrected for the duration of treatment in a multivariate general linear model.

Lotufo et al. 2000, Matilainen et al. 2001). Our findings, however, do not support the idea that androgen-induced changes in established CHD risk factors explain the epidemiological association between MPB and CHD. What may explain our null-finding? First, the degree of MPB and established CHD risk factors may be unrelated, as was found in a study among 1219 males (Ellis et al. 2001). Yet the lack of association between MPB and CHD risk factors contrasts with findings of two cohort studies (Trevisan et al. 1993, Lotufo et al. 2000) and a case-control study (Matilainen et al. 2000) that found associations between MPB and CHD risk factors. We found that levels of fasting glucose and insulin were somewhat lower in balding subjects, which contrasts with the positive associations found between disorders clustered in the metabolic syndrome and MPB (Matilainen et al. 2000). The discrepancy may be the consequence of our study group of $\mathrm{F} \rightarrow \mathrm{M}$ transsexuals in whom endogenous androgens were naturally low at baseline, and in whom androgen administration induced both MPB and strong changes in serum lipids and body weight but not in blood pressure. Secondly, it could be that androgens do not link MPB with established CHD risk factors. Although sensitivity of the scalp to androgens is the important component of the pathophysiology of MPB, it may be unrelated to the epidemiological association between MPB and CHD. Moreover, androgen excess is not always present in men with MPB nor in women with androgenic alopecia (Futterweit et al. 1988, Vexiau et al. 2000), and among subjects in whom androgens have induced MPB CHD morbidity and mortality are not necessarily increased (e.g. $293 \mathrm{~F} \rightarrow \mathrm{M}$ transsexuals during the 2418 person-years of androgen treatment (van Kesteren et al. 1997) and 319 women with PCOS followed for 31 years (Wild et al. 2000)).

Thirdly, some CHD risk factor not studied may be the intermediate. In that case, androgen metabolism and sensitivity is still directly involved, but through a pathway other than classic CHD risk factors. It could be hypothesized that heightened androgen action (Horton et al. 1993, Hibberts et al. 1998, Vierhapper et al. 2001) is present in the balding scalp as well as in endothelium, macrophages and vascular smooth muscle cells, which contain sex steroid receptors (McGill et al. 1980, Hodges et al. 1999). Androgens may negatively affect smooth muscle cell proliferation and endothelial and macrophage function, and consequently relate MPB to CHD. Further, insulin-like growth factor I (IGF-I) is a regulator of skin $5 \alpha$-reductase activity increasing dihydrotestosterone formation (Horton et al. 1993, Signorello et al. 1999). High levels of IGF-I have also been related to an increased risk of vertex baldness (Signorello et al. 1999).

Our study has some potential limitations. MPB evaluation was self-assessed, $\mathrm{F} \rightarrow \mathrm{M}$ transsexuals were unfamiliar with the classification system, and the questionnaire was not internally validated, providing a source of misclassification. The effects of testosterone in humans also depend on the endocrine environment already determined by the sex and age of the studied subjects, and therefore we do not know whether the results would be similar in biological men receiving androgens. Moreover, our study may have been statistically underpowered, since we included only a relatively small group of subjects due to the nature of the treatment indication. Yet this study 
provided a unique and attractive model of $\mathrm{F} \rightarrow \mathrm{M}$ transsexuals in whom androgens induced MPB as well as changes in CHD risk factors.

Changes in several CHD risk factors were rather quick and established within months, while the onset of hair loss appeared only after about 13 years in $50 \%$ of $\mathrm{F} \rightarrow \mathrm{M}$ transsexuals. This is in accord with the observation that in either sex thinning of the hair begins between the ages of 12 and 40 years and that approximately 50\% of Caucasian men have some degree of MPB before the age of 50 (Price 1999). As expected, we found that MPB increased in prevalence and severity with age and duration of androgen administration. Apparently, biological women are as similarly prone to MPB as biological men, when their androgen receptors are exposed to testosterone and its $5 \alpha$-reduced metabolite dihydrotestosterone. Dihydrotestosterone is the important mediator of MPB, as illustrated by the effectiveness of finasteride in stopping MPB (Price 1999) and high production rates in men with MPB (Horton et al. 1993, Hibberts et al. 1998, Vierhapper et al. 2001). In summary, our findings do not support the idea that MPB serves as an indicator of increased CHD risk through androgenic effects on classic CHD risk factors.

\section{Acknowledgements}

We are indebted to Prof. Dr Maarten Boers, Jos A J Megens, Willy H L Harmsen and Alex Katinakis for their contributions to this study.

\section{References}

Asscheman H, Gooren LJG, Megens JAJ, Nauta J, Kloosterboer HJ \& Eikelboom F 1994 Serum testosterone level is the major determinant of the male-female differences in serum levels of high-density lipoprotein (HDL) cholesterol and $\mathrm{HDL}_{2}$ cholesterol. Metabolism 43 935-939.

Dunaif A 1997 Insulin resistance and the polycystic ovary syndrome: mechanism and implications for pathogenesis. Endocrine Reviews $\mathbf{1 8}$ 774-800.

Elbers JMH, Giltay EJ, Teerlink T, Scheffer MA, Asscheman H, Seidell JC \& Gooren LJG 2003 Effects of sex steroids on components of the insulin resistance syndrome in transsexual subjects. Clinical Endocrinology 58 562-571.

Ellis JA, Stebbing M \& Harrap SB 2001 Male pattern baldness is not associated with established cardiovascular risk factors in the general population. Clinical Science 100 401-404.

Ferriman D \& Purdie AW 1979 The inheritance of polycystic ovarian disease and a possible relationship to premature balding. Clinical Endocrinology 11 291-300.

Ford ES, Freedman DS \& Byers T 1996 Baldness and ischemic heart disease in a national sample of men. American Journal of Epidemiology 143 651-657.

Futterweit W, Dunaif A, Yeh HC \& Kingsley P 1988 The prevalence of hyperandrogenism in 109 consecutive female patients with diffuse alopecia. Journal of the American Academy of Dermatology 19 831-836.

Giltay EJ \& Gooren LJ 2000 Effects of sex steroid deprivation/administration on hair growth and skin sebum production in transsexual males and females. Journal of Clinical Endocrinology and Metabolism 85 2913-2921.

Glazer G 1991 Atherogenic effects of anabolic steroids on serum lipid levels. A literature review. Archives of Internal Medicine $\mathbf{1 5 1}$ 1925-1933.

Herrera CR, D'Agostino RB, Gerstman BB, Bosco LA \& Belanger AJ 1995 Baldness and coronary heart disease rates in men from the Framingham Study. American Journal of Epidemiology 142 828-833.

Hibberts NA, Howell AE \& Randall VA 1998 Balding hair follicle dermal papilla cells contain higher levels of androgen receptors than those from non-balding scalp. Journal of Endocrinology 156 59-62.

Hodges YK, Richer JK, Horwitz KB \& Horwitz LD 1999 Variant estrogen and progesterone receptor messages in human vascular smooth muscle. Circulation 99 2688-2693.

Horton R, Pasupuletti V \& Antonipillai I 1993 Androgen induction of steroid 5 alpha-reductase may be mediated via insulin-like growth factor-I. Endocrinology 133 447-451.

Laws A \& Reaven GM 1993 Insulin resistance and risk factors for coronary heart disease. Baillieres Clinical Endocrinology and Metabolism 7 1063-1078.

Legro RS, Kunselman AR, Demers L, Wang SC, Bentle-Lewis R \& Dunaif A 2002 Elevated dehydroepiandrosterone sulfate levels as the reproductive phenotype in the brothers of women with polycystic ovary syndrome. Journal of Clinical Endocrinology and Metabolism 87 2134-2138.

Lesko SM, Rosenberg L \& Shapiro S 1993 A case-control study of baldness in relation to myocardial infarction in men. Journal of the American Medical Association 269 998-1003.

Lotufo PA, Chae CU, Ajani UA, Hennekens CH \& Manson JE 2000 Male pattern baldness and coronary heart disease: the Physicians' Health Study. Archives of Internal Medicine 160 165-171.

Matilainen V, Koskela P \& Keinanen-Kiukaanniemi S 2000 Early androgenetic alopecia as a marker of insulin resistance. Lancet 356 1165-1166.

Matilainen VA, Makinen PK \& Keinanen-Kiukaanniemi SM 2001 Early onset of androgenetic alopecia associated with early severe coronary heart disease: a population-based, case-control study. Journal of Cardiovascular Risk 8 147-151.

McGill HC Jr, Anselmo VC, Buchanan JM \& Sheridan PJ 1980 The heart is a target organ for androgen. Science 207 775-777.

Norwood OT 1975 Male pattern baldness: classification and incidence. Southern Medical Journal 68 1359-1365.

Price VH 1999 Treatment of hair loss. New England Journal of Medicine 341 964-973.

Schnohr P, Lange P, Nyboe J, Appleyard M \& Jensen G 1995 Gray hair, baldness, and wrinkles in relation to myocardial infarction: the Copenhagen City Heart Study. American Heart Journal 130 1003-1010.

Signorello LB, Wuu J, Hsieh C, Tzonou A, Trichopoulos D \& Mantzoros CS 1999 Hormones and hair patterning in men: a role for insulin-like growth factor I? Journal of the American Academy of Dermatology 40 200-203.

Trevisan M, Farinaro E, Krogh V, Jossa F, Giumetti D, Fusco G, Panico S, Mellone C, Frascatore S, Scottoni A et al. 1993 Baldness and coronary heart disease risk factors. Journal of Clinical Epidemiology 46 1213-1218.

van Kesteren PJ, Asscheman H, Megens JA \& Gooren LJ 1997 Mortality and morbidity in transsexual subjects treated with cross-sex hormones. Clinical Endocrinology 47 337-342.

Vexiau P, Chaspoux C, Boudou P, Fiet J, Abramovici Y, Rueda MJ, Hardy N \& Reygagne P 2000 Role of androgens in female-pattern androgenetic alopecia, either alone or associated with other symptoms of hyperandrogenism. Archives of Dermatological Research 292 598-604.

Vierhapper H, Nowotny P, Maier H \& Waldhä usl W 2001 Production rates of dihydrotestosterone in healthy men and women 
and in men with male pattern baldness: determination by stable isotope/dilution and mass spectrometry. Journal of Clinical

Endocrinology and Metabolism 86 5762-5764.

Walker PA, Berger JC, Green R, Laub DR, Reynolds CL \&

Wollman L 1985 Standards of care: the hormonal and surgical sex reassignment of gender dysphoric persons. Archives of Sexual Behavior 14 79-90.
Wild S, Pierpoint T, Jacobs H \& McKeigue P 2000 Long-term consequences of polycystic ovary syndrome: results of a 31 year follow-up study. Human Fertility 3 101-105.

Received in final form 14 August 2003

Accepted 26 September 2003 